\title{
DECISION TREE MODELLING OF E-CONSUMERS' PREFERENCES FOR INTERNET MARKETING COMMUNICATION TOOLS DURING BROWSING
}

\author{
Jolanta Sabaitytė, Vida Davidavičienė, Jarmila Straková, \\ Jurgita Raudeliūnienẻ
}

\section{Introduction}

The rapid development of information communication technologies (ICT) has expanded the possibilities for marketing communication. In order to increase business competitiveness and carry out effective marketing activities, it has therefore become important to acquire knowledge about e-consumers and to identify significant elements that shape their virtual behaviour and influence their decision to buy.

An analysis of scientific literature revealed that there is a gap in knowledge with regards to the e-consumer behaviour of different generations, as customer segments, and their preferences in the purchase phase. The purchase phase is characterised by different internet marketing communication elements, which influence the performance of browsing and searching tasks. The goal of the research presented in this article was to determine the most significant internet marketing communication elements during the purchase phase of the e-consumer journey by performing a browsing task and using the mathematical decision tree approach.

The research methodology consisted of several stages. First, data was collected using eye-tracking technology in order to identify the internet marketing communication tools that are needed in order to perform the browsing task on a selected e-commerce website. Second, the most important elements were selected and their significance established using the CHAID (Chi-squared Automatic Interaction Detector) Decision Tree model. The model then created the preconditions for the evaluation of e-consumers' explicit and tacit reactions to the use of internet marketing communication tools (IMCT) in the purchase phase of the e-consumer journey.
The following research methods were applied: questionnaire, interview, observation and experiment (using biometric technologies, namely, the eye-tracking system (ETS)). ETS is defined as a technology that allows the measurement of individual eye movements to receive information about the visual objects which attract the individual or emotions caused by visual objects; this is done by following the subject's glance and determining the sequence of its movement from one location to another.

\section{Literature Review}

Consumer behaviour in virtual spaces has been the subject of scientific research for several decades. However, due to the dynamics and rapid transformation of the main stakeholders involved in this field, such as consumers and businesses, this topic requires continuous and complex field research (Ahmed et al., 2018; Chung \& Park, 2018; Dabija et al., 2018; Sabaityte \& Davidavičiene, 2018; Raudeliūnienè et al., 2018; Dragos \& Dragos, 2017; Gupta et al., 2018; Nobar \& Rostamzadeh, 2018; Vila \& Kuster, 2012; Vojvodic et al., 2018).

Scientists analyse the behaviour of consumers in virtual spaces in different ways: user-centric aspects, such as issues regarding potential buyer conversions (Chen \& Cheng, 2013; Teo \& Liu, 2007; Vo et al., 2017; Palamidovska-Sterjadovska \& CiunovaShuleska, 2017); analyses of the factors influencing consumer behaviour in virtual spaces (Dennis et al., 2009; Dębkowska, 2017; Khorakian \& Jahangir, 2018); consumer perceptions about the quality of the e-commerce experience (Cristobal et al., 2007); psychological (Choi \& Kwon, 2018; Fuchs et al., 2010; Yadav et al., 2013; Stepaniuk, 2017) and demographic characteristics (Sabaityte \& Davidavičius, 2017; 
Brown et al., 2003; Park \& Yang 2017; Maturo, 2018); risk and benefit perception (Huang et al., 2004; Xue et al., 2017). Other researchers investigate technological characteristics, including the technical specifications of e-commerce websites (Huang \& Benyoucef, 2013; Wang et al., 2016; Davidavičienè \& Sabaitytè, 2014; Davidaviciene, Pabedinskaite, \& Davidavicius, 2017), such as payment (MingYen Teoh et al., 2013; Plateaux et al., 2014) and usability aspects (Diaz et al., 2017; Furtner et al., 2015; Wong et al., 2014). However, the user, as the consumer, remains the essential research subject. The consumer's computer skills and willingness to use the opportunities provided to them by virtual spaces depends on factors such as the social, economic, technological and cultural environment (Yang \& Jolly, 2008; Cabrera Torres, 2013; Fernández-Durán, 2015; Khorakian \& Jahangir, 2018). The e-consumer should therefore be analysed through the lens of the theory of generations. This allows consumers to be grouped according to their year of birth and distinguishes the main characteristic that defines the user, namely age (Roberts \& Manolis, 2000).

The concept of generations has been used in cultures worldwide for many centuries (Kertzer, 1983); in the modern context, the social aspect of this theory is becoming increasingly important. In this research, a generation is treated as a group of people born in a similar year and living in the same historical dimension of the social process. A virtual market profile can be determined for different generations, whereby each generation is distinguished by those characteristics that form a distinct experience and lead to different expectations and reactions to marketing communication tools (Cabrera Torres, 2013; Hiram \& de Run, 2013; Reisenwitz \& lyer, 2007; Šafránková \& Šikýř, 2017; Yang \& Jolly, 2008). In this research, the theory of generations is used as a consumer segmentation tool.

In scientific literature, there are different approaches to the classification of generations. Howe and Strauss (2007) make a distinction between 6 generations of people in the United States (The Greatest, Silent, Baby Boom, X, $Y$ and $Z$ generations), while other scientists focus on 4 generations ( $\mathrm{Li}$ et al., 2013): silent, baby boom, and generations $X$ and $Y$. Levickaitè (2010) makes a distinction between 3 generations based on political, social and technological changes ( $\mathrm{X}, \mathrm{Y}$ and $\mathrm{Z}$ ). Malaysian sociologists, analysing the peculiarities of distance learning in relation to differences in generational behaviours, make a distinction between traditional $\mathrm{X}$ and $\mathrm{Y}$ generations (Ahmad \& Tarmudi, 2012). Chi et al. (2013) and Gursoy et al. (2013) analyse the behaviour of 3 main generations: baby boom, $X$ and $Y$. Based on an analysis of the results of scientific research, it was decided to use the following classification of generations: baby boomers (born 1941-1961); generation $X$ (born 19621982); generation $Y$ (born 1983-1997); and generation Z (born 1998-2018).

Following consumer segmentation on the basis of generational theory, it is important to determine the characteristics of the purchase phase on an e-commerce website. On an e-commerce website, users perform two main tasks, namely browsing and searching (Carmel et al., 1992; Hong et al., 2004; Nielsen \& Pernice, 2013; Maturo \& Di Battista, 2018), in order to purchase. Within the context of consumer behaviour, the different parameters of the elements of internet marketing communication are important for these tasks. An e-commerce website, as the main tool in the purchase phase, presents an abundance of elements supporting the important purchase process. These are elements that give consumers a sense of security (guarantee of security, aftersales service, the existence of a physical shop or home address, certificates of quality, return conditions, the opportunity to pay after receipt of the goods), an overview of the characteristics of the products (price; abundant assortment; a rich range of detailed information including text, images, audio, video, mixed media; product delivery costs; justification of physical product existence e.g. showing the quantity in stock), and functional possibilities (various payment methods; registration; visibility of the shopping cart; comparison of goods; navigation elements such as upper, side menu, and search engine; and contact elements such as comments, e-help, contact form, phone number, and mobile support solutions).

\section{Research Design and Methods}

To obtain the most objective information about the behaviour of different generations in virtual spaces, and taking into consideration the specifics of this research subject, a mixed research method was applied, whereby eyetracking technology was used in combination 
with a comparative statistical study using a decision tree model.

The purpose of this research was to determine which statistically significant internet marketing communication elements customers prefer, as defined by different generational cohorts, during the electronic purchase phase using the decision tree model. The research tasks were: (1) to determine the factual response of the baby boom, $X, Y$ and $Z$ generations to the most appropriate communication elements during the electronic purchase phase while performing a browsing task; (2) to evaluate the non-expressed factual reaction of the different generations to the IMCT elements during the electronic purchase phase while performing a browsing task and to determine which communication elements are statistically significant.

The period of research was November 2015 - May 2016. The experiment was conducted anonymously; all the participants were volunteers who agreed to being tested, namely through eye-tracking of their behaviour. Consent from all participants was received verbally.

To determine the number of participants, the recommendations of international experts, the Nielsen Norman Group and Tobii were used. Strandvall (2009), from the eye-tracking company Tobii, recommends analysing the behaviour of 20 to 50 individuals for quantitative research regarding individuals' behaviour, particularly when the results are analysed alongside those of other research results. A similar position is held by Pernice and Nielsen (2009). They recommend analysing the behaviour of 20 consumers for qualitative consumer research. Since the quantitative research to determine population behaviour is an additional investigation for deepening the understanding of individuals' behaviour during the purchase process, 27 individuals from each generation were invited to take part, thereby bearing in mind the risk that the data from every individual may not be suitable. After processing the research data (108 individuals participated in total) and rejecting respondent data that was unsuitable, the behaviour of 76 individuals on the selected e-commerce website was analysed (19 from the $Z$ generation, 22 from the $Y$ generation, 17 from the $X$ generation, and 18 from the baby boom generation).

During the experiment, data describing the trajectory of the subjects' gaze (the location of the elements and the order of choice) and the intensity of usage during the purchase phase (gaze length in relation to the particular element) were recorded. A remote eye-tracking device, Mirametrix S2, was used for the experiment.

To conduct this study, a browsing task was chosen for analysis. The behaviours of the users in the different age groups were analysed throughout the experiment, in particular with regards to the elements of the e-commerce website respondents chose to use to perform the task. The chosen website for this research was local and had the highest rating for an internet shop operating in Lithuania (Alexa.com). In order to analyse the purchase process behaviour of the different age groups while browsing, the selected consumer product had to be well-known to all the age groups. The chosen product was the Samsung Galaxy S6 mobile phone, which was the best-rated high-end phone in Lithuania at the time of this research (Murin, 2015; Maturo, 2017).

When defining the IMCT preferences for users of different generations, it is reasonable to define the areas of interest for the e-commerce websites under analysis based on the recommendations of Purucker et al. (2013), Chandon et al. (2009), and Brasel and Gips (2008) (see Fig. 1). Because different goals are held for the different pages of the e-commerce website, the pages have different functionality and areas of interest. The areas of interest are therefore distinct for the three e-commerce pages: the homepage, search results and product.

During the study, the researcher maintained their distance from the respondent so as not to encourage unnecessary talk during the test. Respondents were asked to not think aloud, as this could negatively affect the results of the study and encourage actions to be performed faster than the respondent would have done otherwise. During the study, those respondents that moved intensively were calibrated several times and were told that this was routine practice so as to minimise additional emotions that could negatively affect the research. All the tasks were stated aloud; the purpose of the task was clearly identified, and checks were preformed to ensure the respondent understood what to do. Respondents were informed when they could begin each task and what action signalled the end of each task (when the data recording 
was finished). After performing all of the tasks, if the gaze of the respondent was being followed, the respondent was informed about this fact accordingly. In between research sessions, data was cleared and the data that was left on the internet browser was deleted.

During this research, the main eye-tracking metrics (fixation and saccades) were recorded along with other metrics: the scanned area, blinking rate and the size of the pupil. Each of the metrics has its own subcategory: fixation metrics (total fixation number), fixation number in the region of interest (hereinafter ROI), number of fixations in the ROI depending on the length of the text, duration of the fixation, gaze (total fixation duration), the spatial density of the fixation, repeated fixations, exact time of the first fixation, percentage of the participants, measured ROI indicator (all target fixations), saccade metrics (number, amplitude of the saccades, regressing saccades, saccades that reveal marked purposeful shifts), metrics of the scanned parts (duration of the scanned part, length of the scanned part, density of the scanned part), transition matrix, regularity of the scanned part, volume of space calculated

\begin{tabular}{|c|c|c|c|}
\hline $\begin{array}{l}\text { No. } \\
\text { in list }\end{array}$ & $\begin{array}{l}\text { Sub-category } \\
\text { (elements) }\end{array}$ & $\begin{array}{c}\text { Category } \\
\text { (In accordance with Internet } \\
\text { Marketing Communication } \\
\text { Tools) }\end{array}$ & Acronym \\
\hline 7 & Upper search engine box & \multirow{2}{*}{ Web search engine } & IPS1 \\
\hline 23 & Lower search engine box & & IPS2 \\
\hline 8 & Contact us form & Contact form & SF \\
\hline 9 & Phone number & Instant Messaging & $M Z$ \\
\hline $14 a$ & Product photo & \multirow{15}{*}{ E-commerce website } & TEKS1 \\
\hline $14 \mathrm{~b}$ & Discount & & TEKS2 \\
\hline $14 \mathrm{c}$ & Price & & TEKS3 \\
\hline $14 d$ & Physical evidence element & & TEKS4 \\
\hline $14 \mathrm{e}$ & The name of the product & & TEKS5 \\
\hline $14 f$ & Call to action - buy button & & TEKS6 \\
\hline $14 \mathrm{~g}$ & Text characteristics & & TEKS7 \\
\hline $14 \mathrm{~h}$ & Comparison element & & TEKS8 \\
\hline $14 \mathrm{i}$ & Video information & & TEKS9 \\
\hline $14 \mathrm{j}$ & Link to the manufacturer's page & & TEKS10 \\
\hline $14 k$ & Wish list & & TEKS11 \\
\hline $22 a$ & Photo (left product element) & & TEKS12 \\
\hline $22 b$ & Price (left product element) & & TEKS13 \\
\hline $22 c$ & $\begin{array}{l}\text { Call to action - buy button (left product } \\
\text { element) }\end{array}$ & & TEKS14 \\
\hline $22 d$ & Title of the product (left product element) & & TEKS15 \\
\hline 16 & Newsletter & E-mail & EP \\
\hline 18 & Reviews & Comments & KM \\
\hline 20 & FAQ & FAQ & DUK \\
\hline 21 & Blog & Blog & TNK \\
\hline 25 & Social networks & Social networks & SM \\
\hline
\end{tabular}



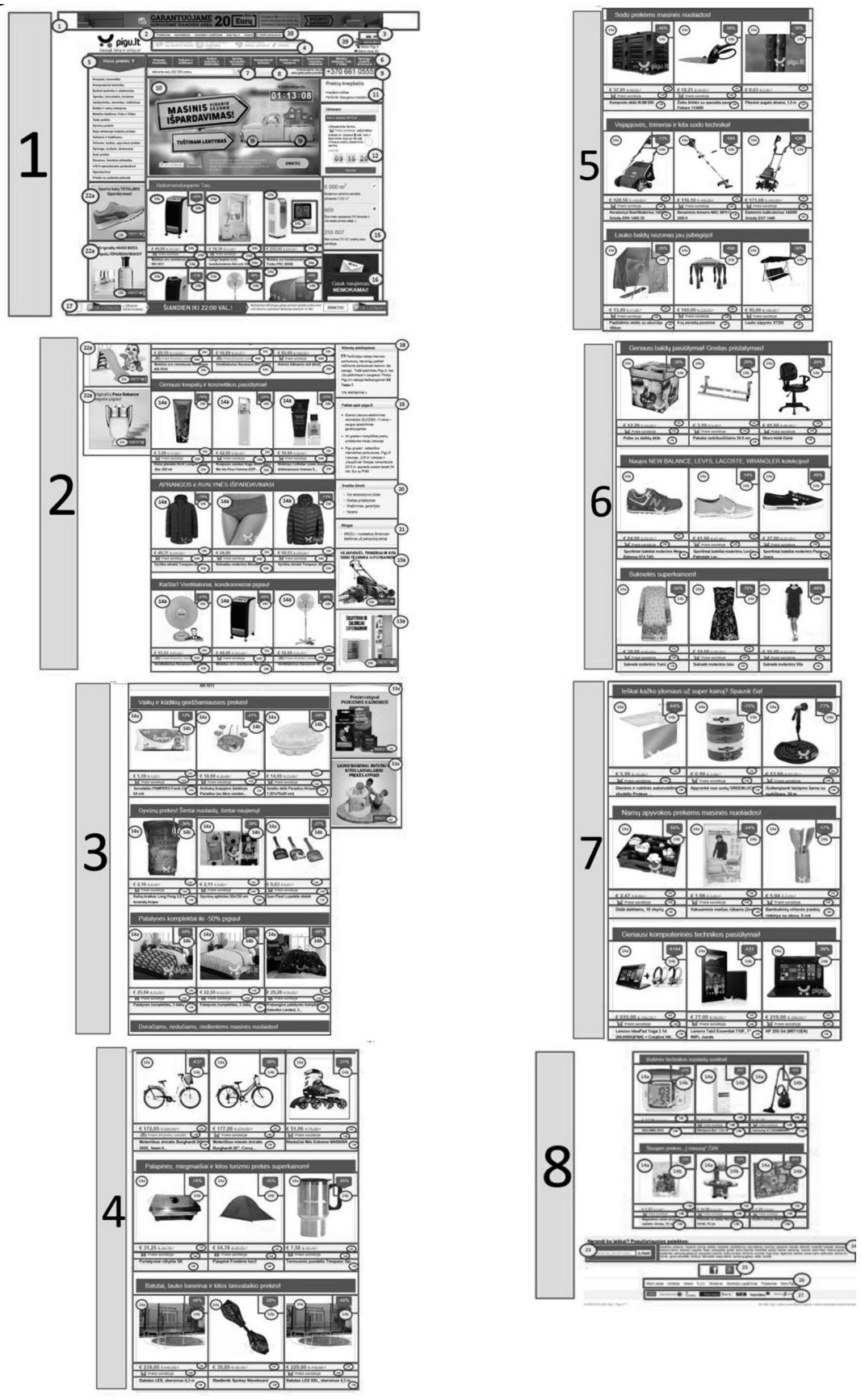
on the basis of the convex hull width, direction of the scanned part, frequency of the saccades and fixations.

The data generated during the eye-tracking research were saved as data tables (.xls) and video material (avi). In order to achieve the purpose of the study, the information on sight fixation was analysed and linked to the area of interest. The information on sight fixation and duration was presented in data tables (.xls), and the determination of the area of interest was done by analysing the eye movement trajectory and sight fixation information from the video material (the performance sequence of the tasks was recorded during the experiment). A set of elements was created for which the fixation of sight was not less than $180 \mathrm{~ms}$. The elements from the general list were, due to their specific features, subsequently assigned as means of internet marketing communication. Acronyms were given to these elements (see Tab. 1) and another data setup prepared with SPSS IBM Statistics software for further work.

Considering the purpose of this study is to identify the preferred elements of online marketing at the purchase phase, decision tree models (DTMs) were applied. DTMs were not only chosen because of their ability to classify elements by group, but also in this particular case to explain the consumer choices with respect to IMCT preferences. There are a number of known DTM methods (CTR, QUEST, CHAID (Exhaustive CHAID) (Kass, 1980)), from which the DTM CHAID (Chi-squared Automatic Interaction Detection) was chosen. The CHAID method was selected on the basis of the specifics of the dependent variable (generation - categorical variable). In addition, the choice was based on the ability of the model to classify the available data by group and its ability to forecast the dependent variables (within the context of this study, the behaviour of different generations) according to known independent variables (in terms of IMCT preferences).

The CHAID method is based on a particular algorithm that includes 3 steps: grouping, separation of the elements and suspension. The decision tree grows by repeatedly applying the algorithm, starting with the root node and finishing with the analysis of all the data that is being used. A classic statistical criterion, Chi-square $\left(x^{2}\right)$, is used in the CHAID DTM. The algorithm determines the most appropriate separation for each independent variable (within the context of this study - IMCT) and continues to select the dependent variable (generation), the separation of which has a statistically significant difference (the lowest value of $p$ in the chi-square significance determination test), which allows the determination of statistically significant IMCT preferences during the study. Under this method, each step identifies the strongest interaction between the relevant generation and the relevant online marketing communication tools. Where the influence on the generations is only slight for the different IMCT elements, they are combined.

The DTM CHAID method, based on Chisquare, enabled the classification of the elements and the prediction of the IMCT preferences; the risk of an incorrect classification was also evaluated. Graphically displaying the results of the analysis as a decision tree enables the hierarchical dependency of the variables to be set.

The method that was applied made it possible to distinguish between those IMCT elements that are statistically significant for different tasks and those elements which determine an increase in consumer engagement in the purchase process. Since a large amount of data was collected during the study, the model allowed the selection of a large group of independent variables to have only a statistically significant influence on the prediction of generational behaviour during the purchase phase in a different task environment (this research focuses on a local shop). In addition, the model enabled the identification of interactions between different users of different ages. The decision tree model for IMCT preferences was compiled using IBM SPSS Statistics software version 20 .

The model was constructed using a data set obtained from the eye-tracking study. The data was categorised and reorganised according to 24 sub-categories (independent variables see Tab. 1). The category "Generation" ["Karta”] (generation $\mathrm{Z}$, generation $\mathrm{Y}$, generation $X$ and BB generation) was chosen as the dependent variable of the constructed model. 24 independent variables were divided into 9 larger categories. The independent variables were measured on a nominal scale $(1-$ the average element fixation is over $180 \mathrm{~ms}, 0$ - the average element fixation is less than $180 \mathrm{~ms}$ ).

The technical conditions for the application 
of the model included a minimum $p$ value of 0.05 for the individual nodes and for the combined categories. The significance values were determined in accordance with the Bonferroni method, which specifies the $p$ value by separating and combining the categories (first by checking the value in Chi-square and then adjusting it according to Bonferroni's value):

$$
B=\sum_{v=0}^{r-1}(-1)^{v} \frac{(r-v)^{I}}{v !(r-v) !}
$$

where: $B$ - Bonferroni indicator for a categorical variable; $I$ - total number of independent variable categories; $r$ - number of statistically significant independent variables after merging the categories; $v$ - number of categories.

The characteristics for creating a decision tree were subsequently identified. The DTM growth limits were chosen: the maximum DTM depth was 3 levels, which indicates the number of DTM levels below the root node; the minimum number of cases for root nodes was 10 cases, with 5 cases for branch nodes. Cases were selected based on a relatively small number of data file observations. The confidence interval, $2^{x}$ statistics and other parameters remained set (as recommended by Pukènas (2009)). As the decision tree growth algorithm includes all variables (categorised or ranked), standardisation was not required. According to the CHAID method, independent interval scale variables are divided into discrete groups. The specified number of such groups is 10 . In setting the parameters, the misclassification costs, i.e. the relative indicated cost of the ranking scale of the dependent variable of the misclassification, is equal across all categories. The variables chosen for the decision tree output are Gain and Index. The nominal and rank scales for the dependent variable Gain is defined as the percentage of the selected category data in the decision tree node in relation to all the data in the selected categories. The nominal and rank scales for the dependent variable Index is defined as the ratio of the percentage of selected category responses to the solution in

\section{Summary of CHAID model specifications / Results of different cohorts' prefe- Tab. 2: rences for IMCT elements while performing a browsing task on the selected local e-commerce website}

\begin{tabular}{c|l|l}
\multicolumn{1}{c|}{ Aspects } & \multicolumn{1}{|c}{ Characteristic } & \multicolumn{1}{c}{ Model Summary } \\
\hline \multirow{4}{*}{ Specifications } & Growing Method & CHAID \\
\cline { 2 - 3 } & Dependent Variables & Generation \\
\cline { 2 - 3 } $\begin{array}{l}\text { Independent Variables (the explanation } \\
\text { of the acronyms of independent variables } \\
\text { is given in Table 1) }\end{array}$ & $\begin{array}{l}\text { IPS1, IPS2, SF, MZ, TEKS1, TEKS2, } \\
\text { TEKS3, TEKS4, TEKS5, TEKS6, TEKS7, } \\
\text { TEKS8, TEKS9, TEKS10, TEKS11, } \\
\text { TEKS12, TEKS13, TEKS14, TEKS15, EP, } \\
\text { KM, DUK, TNK, SM }\end{array}$ \\
\cline { 2 - 3 } & Validation & Cross Validation \\
\cline { 2 - 3 } & Maximum Tree Depth & 3 \\
\cline { 2 - 3 } & Minimum Cases in Parent Node & 10 \\
\cline { 2 - 3 } & Minimum Cases in Child Node & 5 \\
\hline \multirow{2}{*}{ Results } & Independent Variables Included & TEKS4, MZ, IPS1, DUK \\
\cline { 2 - 3 } & Number of Nodes & 9 \\
\cline { 2 - 3 } & Number of Terminal Nodes & 5 \\
\cline { 2 - 3 } & Depth & 3 \\
\hline
\end{tabular}


the decision tree node to the percentage of the responses for the whole sample.

\section{Exploratory Analysis of Data and Discussion}

Tab. 2 provides general information on the compilation of the DTM and consists of two parts: provisions for the formation of the DTM (information on the data used to construct the model) and the results obtained (information about the DTM). The characteristics column provides information about the dependent variable Generation [Karta] and independent variables that were used to compile the specific DTM. The independent variables that are statistically significant for the DTM are highlighted in bold: TEKS4 (within the context of this study - physical evidence), MZ (instant messages), IPS1 (upper search bar), DUK (frequently asked questions). The model consists of 9 nodes (within the context of this study they represent the IMCT preferences), of which 5 are endpoints. The decision tree depth is 3 nodes below the root node, which enables the preference for IMCT elements to be set from a hierarchical point of view.

A graphical presentation of the DTM for the browsing analysis on the local e-commerce website is presented in Fig. 2 . The results reveal that the independent variable TEKS4 (within the context of this study - physical evidence) has the most influence on the dependent variable Generation [Karta]. The right side of the compilation model makes it possible to distinguish the importance of this element for the representatives of the $Z, Y$ and baby boom generations. The importance of physical evidence in the purchasing phase demonstrates the awareness of consumers and the need for security, which applies to both e-commerce websites and the traditional environment and is expressed through the physical evidence elements on the website. Another independent variable with a statistically significant influence on the dependent variable Generation, is IPS1 (upper search bar). The statistical significance of this element shows that it is important, once again, for the representatives of the $Z, Y$ and baby boom generations. The importance of the element is explained through the peculiarities of navigation - consumers that belong to these generations tend to make sure of the physical presence of the e-supplier, and then continue their product search by entering keywords in the search bar. For 20 percent of generation $Y$ and 80 percent of baby boomers, for whom the element of physical evidence and the upper search bar are important, there is another element that is important, namely Frequently Asked Questions (independent variable DUK). The indicated preferences make it possible to notice the inclination of the baby boom generation towards web 1.0 features (FAQ as a static information presentation tool).

The left side of the analysed DTM enables the identification of another statistically significant independent variable $M Z$ (within the context of this research - instant messaging). When performing a browsing task, the significance of this element was noted by $84.6 \%$ of generation $Z, 7.7 \%$ of generation $X$ and $7.7 \%$ of the baby boom generation. The independent variable in the end of DTM node indicates the strong inclination of the $Z, X$ and baby boom generations to support the communication process through this mobile channel.

The created DTM for the purchase phase on the selected local e-commerce website enabled the identification of the statistically significant preferences for online marketing communication tools for the different age groups. However, in order to determine the possibilities of applying a decision tree model solution, it is necessary to assess how informative and appropriate the application of a particular DTM is. In assessing the applicability of the model for the prediction of each generation's behaviour in virtual spaces, the amount of data used for the corresponding generation for each of the identified statistically significant preferences was evaluated (preferential models are expressed through nodes in the graphical representation of the model) and the eligibility of the preferences justified on the basis of the percentile graphs for the dependence of the Gain and Index variables. The analysis of the risk assessment for the application of the constructed DTM was performed by assessing the ability to predict the behaviour of the generations in the virtual space through the correct allocation of preferential IMCT elements to each generation.

Justification of the suitability of the DTM for the behavioural forecast for generation $Z$ for the completed purchase phase follows. When analysing the DTM for the consumer eligibility of IMCT preferences for generation $Z$, the data representing the behaviour of this generation and their distribution was analysed for the 


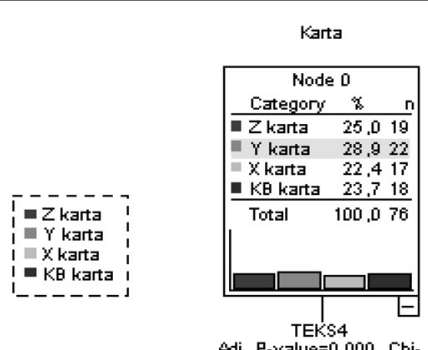

Adj. P-walue $=0,000$, Chi-

square $=45,608, \mathrm{df}=3$

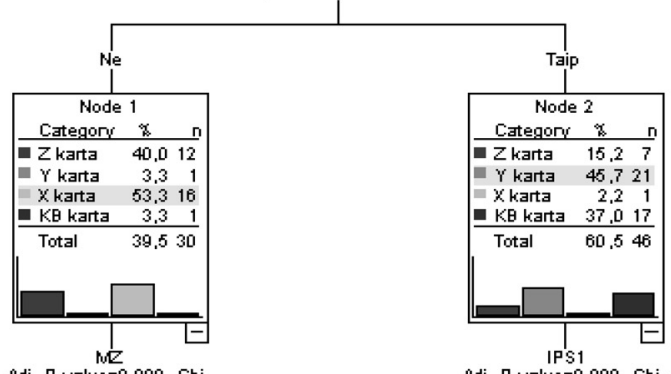

Adj. P-walue $=0,000$, Chi-

Adj. P-value $=0$,óno. Chi-

square $=22,449, \mathrm{df}=3$

square $=25,281, \mathrm{df}=3$
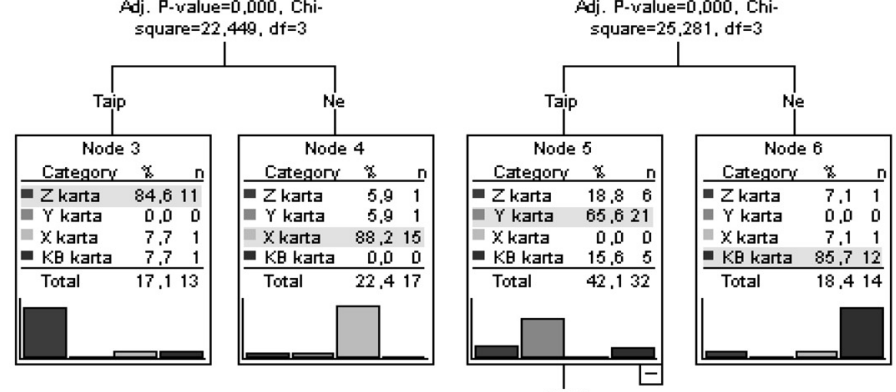

Adj. P-walue $=0,000$, Chi-

square $=18,708, \mathrm{df}=2$

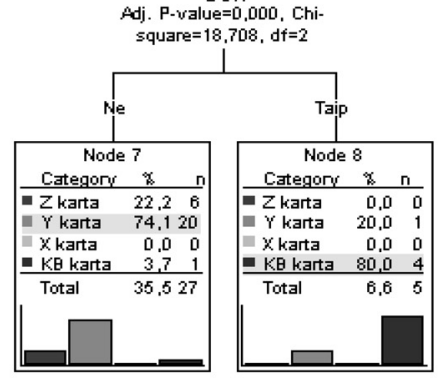

Source: authors 
formation of nodes. Generation Z preferences are expressed as the compiled model nodes 1 , 3, 7, 6, 4 and 8 (see Fig. 2). The information on the Gain variable enabled the identification of the generation $Z$ data which was used in the respective DTM nodes (within the context of this study, for determining the specific IMCT preference) (see Tab. 3). The Index indicator enables the portion of data for generation $Z$ to be set in a particular DTM node. When the Index value is greater than $100 \%$, this means that the portion of data for generation $Z$ in a particular node is larger than the total share of other generations, which indicates the strength of the generation's preference compared to that of the other generations. Based on the Index indicator, node 3 represents the specific preference of the $Z$ generation for instant messages and thus defines the specifics of this generation's behaviour compared to that of the other generations. Also of importance are the preferences in nodes 5 (upper search bar) and 2 (physical evidence).

The suitability of the developed model can be determined by the percentile graph for the dependence of the Gain variable (see Fig. 3a). The graph shows that the dependence curve approaches $100 \%$ rather quickly and settles at that value, which means that the model is informative. Another indicator of the model's suitability is the percentile graph for the dependence of the Index variable (see Fig. 3b). The model is appropriate because the Index value remains close to the initial value $(338.5 \%)$ and then falls sharply to the 100th percentile. Justification of the suitability of the DTM for the behavioural forecast for generation $Y$ for the completed purchase phase follows. When analysing the eligibility of the model, the DTM nodes reflecting the IMCT preferences of generation $\mathrm{Y}$ (Nodes 7, 8, 4, 6 and 3) should be noted. Node 8 shows that the FAQ tool is considered important by $20 \%$ of the representatives of generation $\mathrm{Y}$. It should be stated that the tool is a statistically significant preference for a fifth of the generation $Y$ users, so it must be used at the purchase phase. Other generational preferences are expressed by nodes 2 (physical evidence) and 5 (upper search bar).

Justification of the suitability of the DTM for the behavioural forecast for generation $X$ for the completed purchase phase follows. When analysing the specifics of the purchase phase browsing preferences of generation $X$, DTM nodes $4,3,6,7$ and 8 are considered important. The preference for instant messaging tools is specific to generation $X$ (node $3,7.7 \%$ ). The graphical analysis of the model also identifies physical evidence as important for browsing (node 2, 2.2\%). With regards to how informative the DTM is in relation to the navigation task phase for generation $X$, it is evident from the dependence graphs for the Gain and Index variables that the DTM is informative in relation to the prediction of the behaviour of generation $X$ in virtual spaces.

\section{Fig. 3: (a) Dependence of the Gain variable for generation Z; (b) Dependence of the Index variable for generation $Z$}

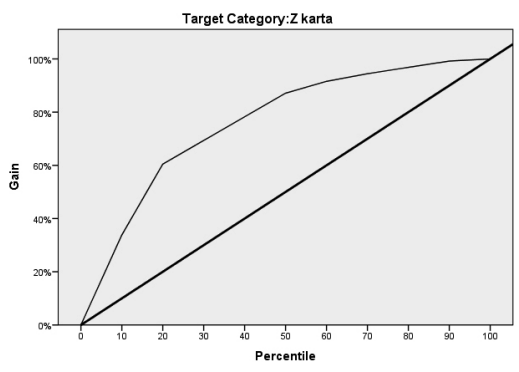

(a)

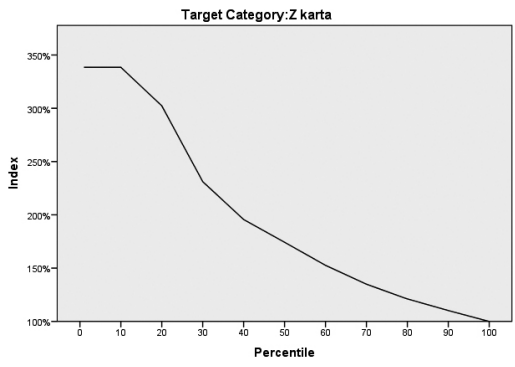

(b) 

Tab. 3: Gains for generation $Z$ nodes (Growing method: CHAID; dependent variable:
generation)

\begin{tabular}{|c|c|c|c|c|c|c|}
\hline \multirow{2}{*}{ Node } & \multicolumn{2}{|c|}{ Node } & \multicolumn{2}{|c|}{ Gain } & \multirow{2}{*}{$\begin{array}{l}\text { Response } \\
\text { rate }\end{array}$} & \multirow{2}{*}{ Index } \\
\hline & $\mathbf{N}$ & Percent & $\mathbf{N}$ & Percent & & \\
\hline 3 & 13 & $17.1 \%$ & 11 & $57.9 \%$ & $84.6 \%$ & $338.5 \%$ \\
\hline 7 & 27 & $35.5 \%$ & 6 & $31.6 \%$ & $22.2 \%$ & $88.9 \%$ \\
\hline 6 & 14 & $18.4 \%$ & 1 & $5.3 \%$ & $7.1 \%$ & $28.6 \%$ \\
\hline 4 & 17 & $22.4 \%$ & 1 & $5.3 \%$ & $5.9 \%$ & $23.5 \%$ \\
\hline 8 & 5 & $6.6 \%$ & 0 & $0.0 \%$ & $0.0 \%$ & $0.0 \%$ \\
\hline
\end{tabular}

Source: authors

Justification of the suitability of the DTM for the behavioural forecast for the baby boom generation for the completed purchase phase follows. The data obtained suggests that the preferences generated by the DTM for the BB generation lie in nodes 6, 8, 3, 7 and 4 . When analysing the data within the context of communication preferences, it is evident that nodes 8 and 3 are specific to this generation. Node 8 reflects a strong generational preference for the FAQ tool $(80.0 \%)$, and node 3 for the instant messaging tool $(7.7 \%)$. The graphical representation of the DTM also clearly reveals the baby boom generation's preference for physical evidence $(37.0 \%)$, as indicated under node 2, and the upper search bar, as indicated under node 5 . To sum up, the baby boom generation, when performing the browsing task in the purchase phase, chooses the most frequently asked questions, instant messages, physical evidence and upper search bar to help them figure out the steps needed to complete the purchase process (FAQ tool), find the product that they need (search element) and make sure that the company active in e-commerce exists and can provide help via telephone (physical elements confirm the existence of the fact, and instant messages are used to contact and clarify the information).

As previously stated, in order to evaluate how informative the research results are in relation to the different generations of users, an analysis of each generation's data was performed on the basis of the percentile graphs for the dependence of the Gain and Index variables. The DTM was found to be appropriate and informative and therefore allows the preferred IMCT elements at the purchase phase while performing a browsing task to be set for the $\mathrm{Z}, \mathrm{Y}, \mathrm{X}$ and $\mathrm{BB}$ generations.
Whilst determining the suitability of the completed model to predict the behaviour of different generations at the purchase phase while browsing on a local e-commerce website, the risks associated with the DTM were further assessed. Inaccuracy in the generationbased electronic consumer behaviour patterns may be due to the incorrect assignment of IMCT preferences to generations. The risk of mistaken generational identity was therefore estimated (model setting provisions: dependent variable category) at $18.4 \%$ (standard error 0.044). The resulting model is therefore quite precise and can be used to predict the behaviour of different generations. When determining the overall accuracy of the DTM, it is advisable to perform a DTM risk assessment for each generation.

After the construction of the model, the probability of correctly predicting the behaviour of generation $Z$ during the purchase phase was found to be $57.9 \%$ with respect to IMCT preferences. This compares to $90.9 \%$ for generation $\mathrm{Y}, 88.2 \%$ for generation $\mathrm{X}$, and $88.9 \%$ for the baby boom generation. The overall accuracy of the model was found to be $81.6 \%$. It can therefore be claimed that the compiled model is fairly accurate when it comes to determining statistically significant IMCT elements.

In summary, it can be said that the representatives of the different generations, when browsing on the selected local e-commerce website, were responsible for statistically significant and generationally unique consumer behaviour with regards to IMCT, in particular paying attention to physical evidence, instant messages, the upper search bar and frequently asked questions. 


\section{Conclusions}

It has been determined that there is currently no comprehensive approach to the system of internet marketing communication. Research into consumer behaviour is being conducted, but the science of management lacks a deeper understanding of the purchase process as seen through consumer preferences and the browsing task interface. Within the context of the technological environment, cyclical models of the life stages of e-consumers are becoming more relevant, in particular with regards to their knowledge of the purchase phase.

For the analysis in this article, types of e-consumers were identified using the theory of generations as a consumer segmentation tool in order to group similar people based on their birth year, which formed the preconditions for the formation of consumer personality and behaviour in a virtual space.

An innovative research methodology was applied to investigate consumer behaviour in a virtual space in order to identify the best solutions for internet marketing communication for different generations during the purchasing phase of an e-consumer's journey. To deepen the knowledge of the purchase phase, an eyetracking study was performed during a browsing task on a selected local e-commerce website. On the basis of the obtained research data, a decision tree model was developed using the CHAID method. The DTM enabled the identification of statistically significant IMCT elements for different generations.

It was established that comparable statistically significant preferences for online marketing communication tools, at the purchase phase during a browsing task, exist for generations $Z$ and $X$, namely for instant messages and physical evidence. For generation $Z$, the upper search bar is also significant. In addition, similarities were found in the behaviours of generation $Y$ and baby boomers with regards to frequently asked questions, which proved to be a statistically significant element. For generation $\mathrm{Y}$, physical evidence and the upper search bar were also statistically significant elements, whereas for baby boomers it was instant messages, although to a lesser degree.

An analysis of how informative and appropriate the compiled DTM was for each generation was performed on the basis of the percentile graphs for the dependence of the
Gain and Index variables. It was determined that the DTM was appropriate and informative for predicting consumer behaviour in the majority of cases.

\section{References}

Ahmad, M. A., \& Tarmudi, S. M. (2012). Generational differences in satisfaction with e-learning among higher learning institution staff. Procedia - Social Behaviour Science, 67, 304-311. https://doi.org/10.1016/j. sbspro.2012.11.333.

Ahmed, R. R., Vveinhardt, J., \& Streimikiene, D. (2017). Interactive digital media and impact of customer attitude and technology on brand awareness: evidence from the South Asian countries. Journal of Business Economics and Management, 18(6), 1115-1134. https://doi.org/ 10.3846/16111699.2017.1400460.

Brasel, S. A., \& Gips, J. (2008). Breaking through fast-forwarding: Brand information and visual attention. Journal of Marketing, 72(6), 31-48. https://dx.doi.org/10.1509/jmkg.72.6.31.

Brown, M., Pope, N., \& Voges, K. (2003). Buying or browsing? An exploration of shopping orientations and online purchase intention. European Journal Marketing, 37, 1666-1684. https://doi.org/10.1108/03090560310495401.

Cabrera Torres, I. (2013). Online NewsSeeking Behavior among Three Generational Cohorts: Baby Boomers, Generation $X$, and Generation $Y$ (Thesis). Rochester Institute of Technology. Retrieved October 12, 2018, from http://scholarworks.rit.edu/theses/964.

Carmel, E., Crawford, S., \& Chen, H. (1992). Browsing in hypertext: A cognitive study. IEEE Transactions on Systems, Man, and Cybernetics, 22(5), 865-884. https://doi. org/10.1109/21.179829.

Chandon, P., Hutchinson, J. W., Bradlow, E. T., \& Young, S. H. (2009). Does in-store marketing work? Effects of the number and position of shelf facings on brand attention and evaluation at the point of purchase. Journal of Marketing, 73(6), 1-17. https://doi.org/10.1509/ jmkg.73.6.1.

Chen, C.-W., \& Cheng, C.-Y. (2013). How online and offline behavior processes affect each other: customer behavior in a cyberenhanced bookstore. Quality \& Quantity, 47, 2539-2555. https://doi.org/10.1007/s11135012-9670-y.

Chi, C. G., Maier, T. A., \& Gursoy, D. (2013). Employees' perceptions of younger 
and older managers by generation and job category. International Journal of Hospitality Management, 34, 42-50. https://doi. org/10.1016/j.ijhm.2013.01.009.

Choi, Y.-T., \& Kwon, G.-H. (2018). New forms of citizen participation using SNS: an empirical approach. Quality \& Quantity, 53(1), 1-17. https://doi.org/10.1007/s11135-018-0720-y.

Chung, C. J., \& Park, H. W. (2018). Beyond data, innovation, social network, and convergence. Quality \& Quantity, 52(2), 515-518. https://doi.org/10.1007/s11135-017-0669-2.

Cristobal, E., Flavián, C., \& Guinalíu, M. (2007). Perceived e-service quality (PeSQ): Measurement validation and effects on consumer satisfaction and web site loyalty. Managing Service Quality, 17(3), 317-340. https://doi.org/10.1108/09604520710744326.

Dabija, D.-C., Bejan, B. M., \& Tipi, N. (2018). Generation X versus millennials communication behaviour on social media when purchasing food versus tourist services. E\&M Economics and Management, 21(1), 191-205. https://doi. org/10.15240/tul/001/2018-1-013.

Davidavičienè, V., \& Sabaitytè, J. (2014). The analysis of research on internet marketing. Business: Theory and Practice, 15(3), 220-233. https://doi.org/10.3846/btp.2014.22.

Davidaviciene, V., Pabedinskaite, A., \& Davidavicius, S. (2017). Social networks in B2B and $\mathrm{B} 2 \mathrm{C}$ communication. Transformations in Business \& Economics, 16(1), 69-84.

Dębkowska, K. (2017). E-services in business models of enterprises in the logistics sector. Business: Theory and Practice, 18(1), 79-87. https://doi.org/10.3846/btp.2017.009.

Dennis, C., Merrilees, B., Jayawardhena, C., \& Wright, L. T. (2009). E-consumer behaviour. European Journal of Marketing, 43, 1121-1139. https://doi.org/10.1108/03090560910976393.

Diaz, J., Rusu, C., \& Collazos, C. A. (2017). Experimental validation of a set of cultural-oriented usability heuristics: e-Commerce websites evaluation. Computer Standards \& Interfaces, 50, 160-178. https://dx.doi.org/10.1016/j.csi.2016.09.013.

Dragos, C. M., \& Dragos, S. L. (2017). Estimating consumers' behaviour in motor insurance using discrete choice models. E\&M Economics and Management, 20(4), 88-102. https://doi.org/10.15240/tul/001/2017-4-007.

Fernández-Durán, J. J. (2015). Defining generational cohorts for marketing in Mexico. Journal of Business Research, 69(2), 435-444. https://doi.org/10.1016/j.jbusres.2015.06.049.
Fuchs, C., Prandelli, E., \& Schreier, M. (2010). The psychological effects of empowerment strategies on consumers' product demand. Journal of Marketing, 74(1), 65-79. https://doi.org/10.1509/jmkg.74.1.65.

Furtner, K. C., Mandl, T., Womser-Hacker, C. (2015). Effects of Auto-Suggest on the Usability of Search in eCommerce. In 14th International Symposium on Information Science (ISI 2015), Zadar, Croatia, 19th--21stMay 2015(pp. 178-190). https://doi.org/10.5281/zenodo.17948.

Gupta, S., Agarwal, A. K., \& Chauhan, A. K. (2018). Social media and its impact on consumers buying behavior with special reference to apparel industry in Bareilly region. SMART Journal of Business Management Studies, 14(2), 17-23. https://dx.doi. org/10.5958/2321-2012.2018.00013.1.

Gursoy, D., Chi, C. G.-Q., \& Karadag, E. (2013). Generational differences in work values and attitudes among frontline and service contact employees. International Journal of Hospitality Management, 32, 40-48. https://doi. org/10.1016/j.ijhm.2012.04.002.

Hiram, T., \& de Run, C. E. (2013). Generational cohorts and their attitudes toward advertising. Tržište/Market, 25(2), 143-160.

Hong, W., Thong, J. Y. L., \& Tam, K. Y. (2004). The effects of information format and shopping task on consumers' online shopping behavior: A cognitive fit perspective. Journal of management information systems, 21(3), 149-184.

Howe, N., \& Strauss, W. (2007). Big Picture. The Next 20 Years. How Customer and Workforce Attitudes Will Evolve. Harward Business Review, 85(8-7), 1-14.

Huang, W., Schrank, H., \& Dubinsky, A. J. (2004). Effect of brand name on consumers' risk perceptions of online shopping. Journal of Consumer Behaviour, 4(1), 40-50. https://doi. org/10.1002/cb.156.

Huang, Z., \& Benyoucef, M. (2013). From e-commerce to social commerce: A close look at design features. Electronic Commerce Research and Applications, 12(4), 246-259. https://dx.doi.org/10.1016/j. elerap.2012.12.003.

Kass, G. V. (1980). An exploratory technique for investigating large quantities of categorical data. Applied Statistics, 29(2), 119-127. https://dx.doi.org/10.2307/2986296.

Kertzer, D. (1983). Generation as a sociological problem. Annual Reviews, 8, 
125-149. https://doi.org/10.2753/RES10609393401065.

Khorakian, A., \& Jahangir, M. (2018). The impact of social network on the innovative behavior of it professionals: what is the role of sharing mistakes? E\&M Ekonomie a Management, 21(3), 188-204. https://doi. org/10.15240/tul/001/2018-3-012.

Kostelić, K., \& Križman Pavlović, D. (2018). Econometric assessment of customers' personality biases and communication preferences correlation. E\&M Ekonomie a Management, 21(3), 141-154. https://doi. org/10.15240/tul/001/2018-3-009.

Levickaite, R. (2010). Generations X, Y, Z: How social networks form the concept of the world without borders (the case of Lithuania). LIMES: Cultural Regionalistics, 3(2), 170-183. https://doi.org/10.3846/limes.2010.17.

Li, X., Li, X. R., \& Hudson, S. (2013). The application of generational theory to tourism consumer behavior: An American perspective. Tourism Management, 37, 147-164. https://doi. org/10.1016/j.tourman.2013.01.015.

Ming-Yen Teoh, W., Choy Chong, S., Lin, B., \& Wei Chua, J. (2013). Factors affecting consumers' perception of electronic payment: an empirical analysis. Internet Research, 23(4), 465-485. https://doi.org/10.1108/IntR-09-20120199.

Murin, E. (2015). Skubantiems: geriausi išmanieji telefonai $2015 \mathrm{~m}$. rudeniui. Retrieved August 12, 2016, from http://www.technologijos. It/n/technologijos/gsm/S-50454/straipsnis/ Skubantiems-geriausi-ismanieji-telefonai2015-m-rudeniui?l=2\&p=1.

Nielsen, J., \& Pernice, K. (2013). Eyetracking Web Usability. New Riders.

Nobar, H., \& Rostamzadeh, R. (2018). The impact of customer satisfaction, customer experience and customer loyalty on brand power: empirical evidence from hotel industry. Journal of Business Economics and Management, 19(2), 417-430. https://doi. org/10.3846/jbem.2018.5678.

Palamidovska-Sterjadovska, N., \& CiunovaShuleska, A. (2017). An integrated model of customer loyalty in the Macedonian mobile service market. E\&M Ekonomie a Management, 20(2), 199-215. https://doi.org/10.15240/ tul/001/2017-2-015.

Park, Y. J., \& Yang, G. S. (2017). Personal network on the Internet: How the socially marginalized stay marginalized in personal network diversity and multiplicity. Telematics and Informatics, 34(1), 1-10. https://doi. org/10.1016/J.TELE.2016.04.001.

Pernice, K., \& Nielsen, J. (2009). How to Conduct Eyetracking Studies. Nielsen Norman Group.

Plateaux, A., Lacharme, P., Jøsang, A., \& Rosenberger, C. (2014). One-time biometrics for online banking and electronic payment authentication. In International Conference on Availability, Reliability, and Security (pp. 179-193). https://doi.org/10.1007/978-3-319-10975-6_14.

Pukènas, K. (2009). Kokybiniy duomeny analizė SPSS programa. Kaunas: Lietuvos kūno kultūros akademija.

Purucker, C., Landwehr, J. R., Sprott, D. E., \& Herrmann, A. (2013). Clustered insights: Improving eye tracking data analysis using scan statistics. International Journal of Market Research, 55(1), 105-130. https://doi. org/10.2501/IJMR-2013-009.

Raudeliūnienè, J., Davidavičienè, V., Tvaronavičienè, M., \& Jonuška, L. (2018). Evaluation of advertising campaigns on social media networks. Sustainability, 10(4), 1-14. https://doi.org/10.3390/su10040973.

Reisenwitz, T., \& lyer, R. (2007). A comparison of younger and older baby boomers: investigating the viability of cohort segmentation. Journal of Consumer Marketing, 24(4), 202-213. https://doi. org/10.1108/07363760710755995.

Roberts, J. A., \& Manolis, C. (2000). Baby boomers and busters: an exploratory investigation of attitudes toward marketing, advertising and consumerism. Journal of Consumer Marketing, 17(6), 481-497. https://doi.org/10.1108/07363760010349911.

Sabaitytè, J., \& Davidavičienè, V. (2018). The analysis of internet marketing research directions. Marketing and digital technologies = Маркетинг і цифрові технології, 2(1), 7-20. https://doi.org/10.15276/mdt.2.1.2018.1.

Sabaitytè, J., \& Davidavičius, S. (2017). Challenges and solutions of adopting public electronic services for the needs of $\mathrm{Z}$ generation. International journal of learning and change, 9(1), 17-28. https://doi. org/10.1504/IJLC.2017.084242.

Šafránková, J. M., \& Šikýř, M. (2017). Sustainable development of the professional competencies of university students: Comparison of two selected cases from the Czech Republic. Journal of Security \& 
Sustainability Issues, 7(2), 321-333. https://doi. org/10.9770/jssi.2017.7.2(12).

Stepaniuk, K. (2017). BLOG content management in shaping pro recreational attitudes. Journal of Business Economics and Management, 18(1), 146-162. https://doi.org/ 10.3846/16111699.2017.1280693.

Strandvall, T. (2009). Guidelines for Using the Retrospective Think Aloud Protocol with Eye Tracking. Tobii Technology. Retrieved May 12, 2012, from https://stemedhub.org/ resources/2181/download/RTA_guidelines_ eyetracking_tobii_shortpaper.pdf.

Teo, T., \& Liu, J. (2007). Consumer trust in e-commerce in the United States, Singapore and China. Omega, 35(1), 22-38. https://doi. org/10.1016/j.omega.2005.02.001.

Vila, N., \& Kuster, I. (2012). The role of usability on stimulating SME's online buying intention: an experiment based on a ficticius web site design. Quality \& Quantity, 46(1), 117-136. https://doi.org/10.1007/s11135-0109332-x.

Vo, L. Van, Le, H. T., Le, D. V., Phung, M. T., Wang, Y.-H., \& Yang, F.-J. (2017). Customer Satisfaction and Corporate Investment Policies. Journal of Business Economics and Management, 18(2), 202-223. https://doi.org/ 10.3846/16111699.2017.1280845.

Vojvodic, K. D., Sosic, M. D. M., \& Zugic, J. D. (2018). Rethinking impulse buying behaviour: Evidence from generation $Y$ consumers. Casopis za ekonomiju i trzisne komunikacije, 8(1), 55-71. https://dx.doi. org/10.7251/EMC1801055V.

Wang, W.-T., Wang, Y.-S., \& Liu, E.-R. (2016). The stickiness intention of group-buying websites: The integration of the commitmenttrust theory and e-commerce success model. Information \& Management, 53, 625-642. https://doi.org/10.1016/j.im.2016.01.006.

Wong, W., Bartels, M., \& Chrobot, N. (2014). Practical eye tracking of the ecommerce website user experience. In International Conference on Universal Access in HumanComputer Interaction (pp. 109-118). https://doi. org/10.1007/978-3-319-07509-9_11.
Xue, K., Yang, C., \& Yu, M. (2017). Impact of new media use on user's personality traits. Quality \& Quantity, 52, 739-758. https://doi. org/10.1007/s11135-017-0485-8.

Yadav, M. S., de Valck, K., Hennig-Thurau, T., Hoffman, D. L., \& Spann, M. (2013). Social commerce: a contingency framework for assessing marketing potential. Journal of Interactive Marketing, 27(4), 311-323. https://doi.org/10.1016/j.intmar.2013.09.001.

Yang, K., \& Jolly, L. D. (2008). Age cohort analysis in adoption of mobile data services: gen Xers versus baby boomers. Journal of Consumer Marketing, 25(5), 272-280. https://doi.org/10.1108/07363760810890507.

Jolanta Sabaityte, Ph.D.

Vilnius Gediminas Technical University

Business Management Faculty Department of Business Technologies and Entrepreneurship Lithuania

Jolanta.sabaityte@vgtu.It

Prof. Vida Davidavičienè, Ph.D. Vilnius Gediminas Technical University Business Management Faculty Department of Business Technologies and Entrepreneurship Lithuania vida.davidaviciene@vgtu.It

Ing. Jarmila Straková, Ph.D. Institute of Technology and Business in České Budějovice Department of Management Czech Republic strakova@mail.vstecb.cz

Prof. Jurgita Raudeliūnienè, Ph.D.

Vilnius Gediminas Technical University Business Management Faculty Department of Business Technologies and Entrepreneurship Lithuania Jurgita.raudeliuniene@vgtu.It 


\title{
Abstract
}

\section{DECISION TREE MODELLING OF E-CONSUMERS' PREFERENCES FOR INTERNET MARKETING COMMUNICATION TOOLS DURING BROWSING}

\author{
Jolanta Sabaitytè, Vida Davidavičienè, Jarmila Straková, \\ Jurgita Raudeliūnienè
}

The successful development of internet marketing is based on scientifically proven decisions designed for the comprehensive analysis and evaluation of internet marketing communication tool selection. Different layers of internet marketing phenomena, such as communication tool profiles and characteristics of customers and strategies for different stages of purchase models, are widely analysed. However, it has been noted that modern management theories lack scientific research on the comprehensive analysis and evaluation of internet marketing communication tools, including the relevant characteristics of electronic consumers profiles based on their generational aspects and their life cycle stages. It is therefore necessary to analyse the stages of an electronic consumer's journey and define the most relevant communication tools and application uses during every stage by aiming to improve customer satisfaction and marketing performance. The goal of this research is to determine the most significant internet marketing communication elements in the purchase phase of the electronic consumer journey cycle using the mathematical decision tree approach for different types of customers, using the generation theory as a segmentation tool. The literature analysis on electronic consumer's behaviour, generation theory application possibilities in marketing and internet marketing communication tools was carried out. The research methodology includes eye-tracking and descriptive and comparative statistical analysis methods (decision tree models), which create the preconditions for the evaluation of electronic consumers' explicit and tacit reactions to the use of internet marketing communication tools during the purchase phase of an electronic consumer's journey. It was established that comparable statistically significant different preferences for internet marketing communication tools, at the purchase phase during a browsing task, exist for baby boomers, $X, Y$ and $Z$ generations.

Key Words: Internet marketing, communication, customer behaviour, internet marketing communication tool, e-commerce.

JEL Classification: M15, M31.

DOI: 10.15240/tul/001/2019-1-014 